\title{
Two-dimensional patterns of human enamel thickness on deciduous (dm1, dm2) and permanent first (M1) mandibular molars
}

\author{
Patrick Mahoney* \\ School of Anthropology and Conservation, University of Kent, Marlowe Building, Canterbury, Kent CT2 7NR, UK
}

\section{A R T I C L E I N F O}

Article history:

Accepted 26 November 2009

\section{Keywords:}

Average enamel thickness

Linear enamel thickness

Dentine area

Enamel cap

\begin{abstract}
A B S T R A C T
Objective: To characterise patterns of enamel thickness on deciduous $(\mathrm{dm} 1, \mathrm{dm} 2)$ and permanent first (M1) mandibular molars and evaluate these against functional and morphological interpretative models.

Methods: Histological sections of mesial and distal cusps from 69 unworn molars were produced and examined using transmitted light microscopy. Enamel cap area, dentine area, as well as average and linear measurements of enamel thickness were recorded from digital images of the sections using image analysis software. Comparisons were made along the molar row, and between the mesial and distal sections of each tooth, using univariate and multivariate inferential statistics.

Results: The enamel cap area, dentine area, and average enamel thickness increased from the anterior to the posterior molars. The greatest proportional increase in linear enamel thickness occurred between the outside surface of the lingual cusps when dm1 was compared to $d \mathrm{~m} 2$, and between the outside surface of the buccal cusps when $\mathrm{dm} 2$ was compared to M1. The enamel cap area increased from the mesial to the distal sections in M1. Dentine area decreased from the mesial to distal sections in dm1. Enamel cap and dentine areas did not change across $\mathrm{dm} 2$.

Conclusion: Results for the deciduous molars are interpreted within a functional model of mastication, in which the $\mathrm{dm} 2$ dissipates less laterally orientated loads compared to $\operatorname{dm} 1$. Differences in enamel thickness between $\mathrm{dm} 2$ and $\mathrm{M} 1$ support previous functional interpretations for this permanent molar. Some mesial-distal results are not easily explained from either a functional or a morphological perspective and suggest an underlying developmental constraint.
\end{abstract}

(C) 2009 Elsevier Ltd. All rights reserved.

\section{Introduction}

The enamel coating on human teeth develops as secretory ameloblast cells move away from the underlying dentine towards the future outer surface and differentiate down along the enamel-dentine interface in a cervical direction. ${ }^{1}$ Measures of the final thickness of that coating have provided important insights into primate taxonomic status ${ }^{2-7}$ and dietary adaptations. ${ }^{8-13}$ Others have related variations in enamel thickness upon a single tooth and along the molar row to functional and morphological interpretative models. ${ }^{14-16}$ Most of these latter studies have focused upon the permanent dentition. The objective in the present study is to characterise deciduous and permanent first molar enamel thickness in a sample of modern human juveniles, and to evaluate the findings against the interpretative models.

\footnotetext{
* Tel.: +44 01227 827927; fax: +44 01227827289.

E-mail address: p.mahoney@kent.ac.uk. 
Table 1 - Linear enamel thickness measurements.

\begin{tabular}{|c|c|c|}
\hline Abbreviation $^{a}$ & Surface & Definition and measurement \\
\hline BST & Lateral & $\begin{array}{l}\text { Outer buccal enamel. Maximum thickness of the buccal surface of the } \\
\text { buccal cusp perpendicular to the dentine-enamel junction (EDJ). }\end{array}$ \\
\hline BCT & Cusp tip & $\begin{array}{l}\text { Buccal cusp tip. Thickness of the buccal cusp, measured from the tip of the } \\
\text { dentine horn to the tip of the occlusal enamel cusp. }\end{array}$ \\
\hline BOT & Inner & $\begin{array}{l}\text { Buccal occlusal slope. Maximum thickness of the occlusal surface of the } \\
\text { buccal cusp perpendicular to the EDJ. }\end{array}$ \\
\hline OFT & Occlusal fovea & $\begin{array}{l}\text { Central fossa. Thickness of the central fossa in the occlusal basin, } \\
\text { perpendicular to the EDJ. }\end{array}$ \\
\hline LOT & Inner & $\begin{array}{l}\text { Lingual occlusal slope. Maximum thickness of the occlusal surface of the } \\
\text { lingual cusp perpendicular to the EDJ. }\end{array}$ \\
\hline LCT & Cusp tip & $\begin{array}{l}\text { Lingual cusp tip. Thickness of the lingual cusp, measured from the tip of } \\
\text { the dentine horn to the tip of the occlusal enamel cusp. }\end{array}$ \\
\hline LST & Lateral & $\begin{array}{l}\text { Outer lingual enamel. Maximum thickness of the lingual surface of the } \\
\text { lingual cusp perpendicular to the EDJ. }\end{array}$ \\
\hline \multicolumn{3}{|c|}{$\begin{array}{l}\text { a BST corresponds to measurement LT(B) from Beynon and Wood, }{ }^{64} \text { and Grine and Martin }{ }^{3} \text {. LTB from Grine, }{ }^{22} \text { and BCW from Schwartz. }{ }^{65} \\
\text { BCT corresponds to measurement CT(B) from Beynon and Wood, }{ }^{64} \text { and Grine and Martin. }{ }^{3} \text { BCT from Schwartz, }{ }^{65} \text { CTB from Grine, }{ }^{22} \text { and BCTTIP } \\
\text { from Suwa and Kono. }{ }^{51} \\
\text { BOT corresponds to measurement OT(B) from Beynon and Wood, }{ }^{64} \text { and Grine and Martin. }{ }^{3} \text { BOB from Schwartz, }{ }^{65} \text { and ' } h \text { ' from Grine. }{ }^{22} \\
\text { OFT corresponds to MOB from Schwartz. }{ }^{65} \\
\text { LOT corresponds to measurement OT(L) from Beynon and Wood, }{ }^{64} \text { and Grine and Martin. }{ }^{3} \text { LOB from Schwartz, }{ }^{65} \text { and 'i' from Grine. }{ }^{22} \\
\text { LCT corresponds to measurements CT(L) from Beynon and Wood, }{ }^{64} \text { and Grine and Martin. }{ }^{3} \text { LCT from Schwartz, }{ }^{65} \text { CTL from Grine. }{ }^{22} \text { LCTTIP } \\
\text { from Suwa and Kono. }{ }^{51} \\
\text { LST corresponds to measurement LT(L) from Beynon and Wood, }{ }^{64} \text { and Grine and Martin. }{ }^{3} \text { LTL from Grine. }{ }^{8} \text { LCW from Schwartz. }{ }^{65}\end{array}$} \\
\hline
\end{tabular}

\subsection{Background}

\subsubsection{Buccal-lingual comparisons of permanent molar enamel} thickness

The movement of the mandible during mastication (the chewing cycle) has been subdivided into phases. ${ }^{17,18}$ Each of these phases transmits different masticatory loads (more vertical crushing and grinding movements, and more lateral shearing) to the molar cusps as the mandible moves through the chewing cycle. ${ }^{19,20}$ These functional differences across the crown surface are reflected by variations in enamel distribution. ${ }^{21}$ This is seen on M1, where the lingual cusps (metaconid and entoconid) provide mainly shearing surfaces, and the buccal cusps (protoconid and hypoconid), grinding and crushing surfaces. The occlusal slopes (see Table 1 and Fig. 1 for definitions) on buccal cusps can have thicker enamel compared to the lingual cusps. ${ }^{22,23}$ This, combined with other morphological differences between the cusps, such as the relatively wide supporting base and thick outer 'buttressing' layer of enamel on the buccal cusps, is thought to increase resistance to the greater functional demands, providing more resistance to wear as well the potential for cusp fracture. ${ }^{21,22,24}$

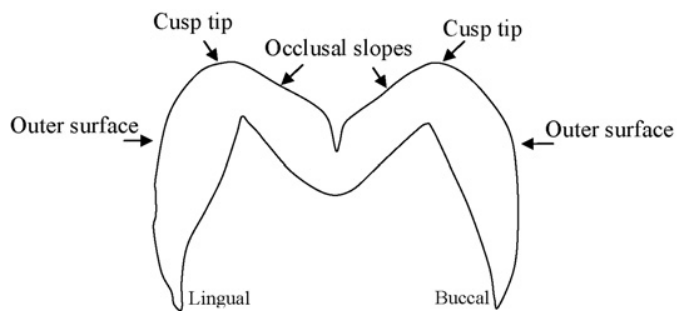

Fig. 1 - Enamel surfaces.
1.1.2. Mesial-distal comparisons of permanent molar enamel thickness

Less is known about enamel thickness over modern human M1 distal cusps (hypoconid and entoconid). Shillingburg and Grace $^{25}$ reported values from mesial-distal sections through M1s. Differences in mean values between the cusps were found (see their Table 12 and the level 6 measurements), but no inferential statistical analyses were undertaken. Others have presented data for small samples, but variation between cusps was not a focus in their studies. ${ }^{2,26}$ Smith et al. ${ }^{7}$ reported increased distal average enamel thickness (AET) compared to mesial sections from permanent mandibular molars in Pan (M1-2) and Pongo (M1-3).

The most extensive study of whole M1 crown enamel distribution in modern humans is by Kono et al. ${ }^{16}$ and Kono. ${ }^{27}$ Using a methodology that produced a three-dimensional (3D) model, Kono et al. ${ }^{16}$ reported average and maximum molar enamel thickness measurements for a small sample, showing that the pattern of mesial cusp enamel thickness did not necessarily transfer to the distal cusps. Distal cusps were found to have thicker enamel compared to mesial cusps, and the hypoconid had the thickest lateral enamel overall. These findings were replicated by $\mathrm{Kono}^{27}$ using a temporally mixed sample (archaeological and present day) of modern humans, though an inferential statistical analysis was not undertaken between the cusps.

1.1.3. Enamel thickness along the permanent molar row Studies of histological thin sections of mesial molar cusps have identified patterns in enamel thickness along the permanent tooth row. These patterns have been related to functional and morphological interpretative models, though one is not necessarily mutually exclusive of the other.

Average and relative enamel thickness (RET) increases posteriorly in human mandibular molars, as well as Pan, ${ }^{22,28,29}$ 
and a similar increase in linear thickness is seen on the occlusal slopes and cusp tips along the maxillary molar row. ${ }^{15}$ Some have related this pattern in humans to a theoretical biomechanical model of mastication, ${ }^{30}$ in which the mandible acts like a class III lever. Under this model, bite force is predicted to increase posteriorly along the molar row. Therefore, the thicker enamel on posterior human molars is thought to reflect an increase in bite force magnitude. ${ }^{15,23}$ Findings from some experimental studies support this biomechanical model. ${ }^{31-33}$

Others argue that increased RET on human third molars is not necessarily a functional response to increased bite force. ${ }^{22}$ Instead, the thicker third molar enamel may be related to a morphological change, whereby a reduction in crown size is facilitated by a reduced dentine component. ${ }^{22}$ Therefore, in this interpretation, relatively thicker enamel is not related to bite force, which is similar to the situation posed for Papio. ${ }^{34}$ Some also question the idea that the human mandible acts as a class III lever, and argue instead that the mandible acts more like a constrained lever during mastication. ${ }^{35,36}$ Under this model, bite force is predicted to decline in posterior molars, as way of protecting the temporomandibular joint. Theoretical computer simulations and some experimental data support this proposal. ${ }^{37-40}$

Studies report patterns in enamel symmetry (thickness disparity and equality) between buccal and lingual cusps along the molar row. Third maxillary molars display increased thickness equality between cusp tips compared to anterior molars. ${ }^{15}$ These findings have been related to the way that maxillary and mandibular molars interdigitate. Differences in symmetry on maxillary molars may facilitate relatively more crushing and grinding posteriorly, and more shearing anteriorly due to the greater lateral excursion of the mandible during chewing. ${ }^{41}$ Therefore, this interpretation is based upon the direction of the applied force (i.e., vertical vs. laterally loading). Patterns of enamel symmetry have also been related to the helicoidal wear plane along the maxillary row, but these do not always transfer to the mandibular molars.

\subsubsection{Enamel thickness in deciduous molars}

Three previous studies have examined deciduous enamel thickness from histological thin sections of mesial mandibular molar cusps. No study has examined distal sections of the deciduous molars. Gantt et al. ${ }^{42}$ recorded measures of linear enamel thickness from a geographically mixed sample of dm1 and dm2. Aiello et al. ${ }^{43}$ reported RET values for a small sample $(n=3)$ of $d m 1$ and $d m 2$. Grine ${ }^{22}$ included dm2 in his study. Their results follow some trends seen in enamel distribution on permanent molars. Enamel thickness increased along the molar row. The dm2 also had thinner enamel compared to permanent molars. The absence of data for distal cusps has made it difficult to evaluate deciduous enamel thickness against a functional or morphological interpretative model. Experimental data for bite force in children is also limited, though preliminary results from a recent large scale unpublished study ${ }^{44}$ indicates bite force production may decrease anteriorly along the molars.

\subsubsection{Methods for measuring enamel thickness}

Two (2D) and three-dimensional (3D) methods are available for studying enamel thickness. Histological methods are routinely used to produce a $2 \mathrm{D}$ plane of section through a tooth. This is a destructive method. Often, these sections are produced for studies of dental development to examine growth rates and formation times, and are then measured opportunistically for studies of enamel thickness. ${ }^{29,45}$

Non-destructive microtomographic imaging techniques produce 2D planes of section ${ }^{46}$ and $3 \mathrm{D}$ reconstructions of the whole tooth crown. ${ }^{16}$ Generally, these different techniques have identified similar broad trends in enamel thickness when several taxa are examined (e.g., gorillas have thin enamel compared to thick enamel of humans). ${ }^{47}$ However, recent findings indicate that these different techniques may not always give the same answer. Three-dimensional values for RET from Australopith taxa differed to previous published 2D values. ${ }^{13}$ This was due in part to differences in enamel distribution over the molars, which was much thicker at the tips in the Australopiths compared to humans. Because of this, measurements through the tips were erroneously exaggerated in the 2D sections. However, similar differences between the techniques have not been reported for modern humans. Furthermore, recent 3D measures of AET reported for modern human permanent mandibular first and third molars, ${ }^{46,48}$ as well as 2D measures from sections, ${ }^{29}$ all lie well within the range reported from 2D measures taken from microtomographic methods. ${ }^{46}$

\section{Materials and methods}

Sixty-nine mandibular molars were selected from archaeological samples of modern human juveniles $(n=26)$ from England and Scotland. The juveniles were curated by the Powell Cotton Museum, Hull and East Riding Museum, The National Museums of Scotland, The Marischal Museum, and the University of Kent. An effort was made in the present study to only select unworn teeth. This was achieved by visiting several institutions, some of which curate large collections of human juvenile skeletons. This provided a large sample size, from which the dental sample was chosen. Therefore values for enamel thickness from both the deciduous and permanent molars did not include measurements based upon reconstruction due to wear (Fig. 2). The dental sample comprised of erupted $\operatorname{dm} 1(n=21), d m 2(n=22)$, and M1 $(n=26)$. The sex of the juveniles was not known. Molars showing external or

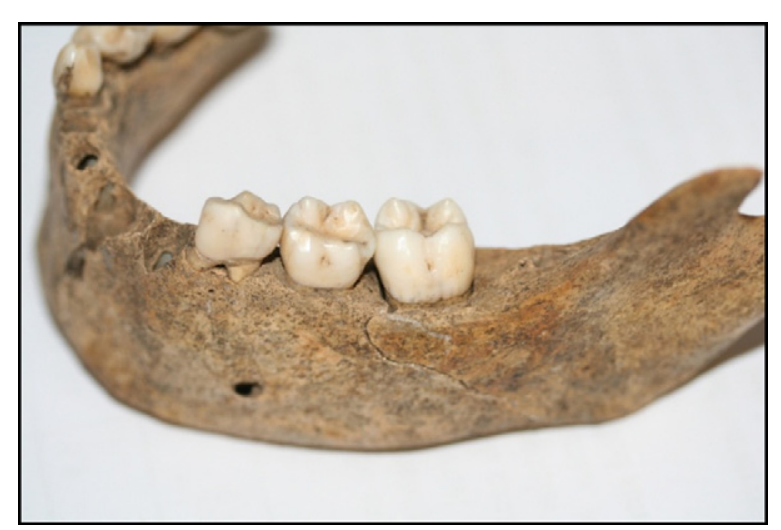

Fig. 2 - Erupted but unworn dm1, dm2, and M1. 
internal signs of hypoplastic defects (see Mahoney ${ }^{45}$ his Fig. 1) were removed from the study.

Measures of enamel thickness were recorded from 2D histological sections. Fifteen of the M1 sections already existed, and dental development from microstructure was previously reported in Mahoney. ${ }^{45}$ The enamel thickness measures are reported here. Histological sections of the deciduous molars were produced to study enamel development (enamel secretion rates; variation in cusp initiation) which is scarcely reported in the literature. The enamel thickness measures for the deciduous molars are reported here.

\subsection{Sample preparation and obliquity}

Each molar was moulded prior to removal for sectioning, and an epoxy cast was prepared. ${ }^{49}$ Following this a standard histological sectioning procedure was followed, ${ }^{50}$ and both mesial (protoconid and metaconid) and distal (hypoconid and entoconid) sections were produced. After embedding the molars in a polyester resin, longitudinal sections between 180 and $200 \mu \mathrm{m}$ were taken (Buehler ${ }^{\mathbb{R}}$ Isomet low speed). The sections past through the tips of the dentine horns and the tips of the enamel cusps.

Both Smith et al. ${ }^{7}$ and Suwa and Kono ${ }^{51}$ have shown that an oblique 2D section, a section that does not show a complete dentine horn tip and occlusal enamel cusp tip, can affect the measurements produced. Obliquity in this study was minimized in two ways. First, following an approach taken by Reid et al. ${ }^{52}$ and Dean and Schrenck ${ }^{53}$ two sections were produced for the mesial cusps; one taken slightly distal to the protoconid and metaconid cusp tips, the other slightly mesial. These sections were then lapped down to $100-120 \mu \mathrm{m}$ using a graded series of grinding pads (Buehler ${ }^{\mathbb{R}}$ ) to reveal the EDJ at the tips of the dentine horns and the maximum extension of the cervical enamel. The section with the ideal plane was then selected for the study; any section that was clearly oblique to the ideal plane (i.e., did not show a complete dentine horn tip) were not included in the study. The process was repeated for the distal cusps. These sections were then polished with a $0.3 \mu \mathrm{m}$ aluminium-oxide powder, placed in an ultrasonic bath to remove surface debris, dehydrated through a series of alcohol baths, cleared (using Histoclear ${ }^{\mathbb{R}}$ ), and mounted with a cover slip using a xylene-based mounting medium (DPX $\left.{ }^{\mathbb{R}}\right)$. Sections were examined under a high powered light microscope (Olympus BX51), and images were taken using a digital microscope camera (Olympus DP25). Enamel thickness was recorded using imaging software (Olympus Cell ${ }^{\mathrm{D}}$ ).

The obliquity of the slides produced was evaluated though comparisons with Suwa and Kono. ${ }^{51}$ The linear measurements BCT and LCT (discussed below) taken through the mesial M1 cusps are comparable to the measurements BCTTIP and LCTTIP from the mesial M1 cusps in their study. Suwa and Kono ${ }^{51}$ show that sections offset from the ideal plane will produce a coefficient of variation (CV) much greater than the CV they report. They report a CV of 17.0 and 14.2 for BCTTIP and LCTTIP respectively. In this study, the CV of 22.4 and 18.5 for BCT and LCT lies close to their reported values, and suggests that the planes of section reported here were not oblique.

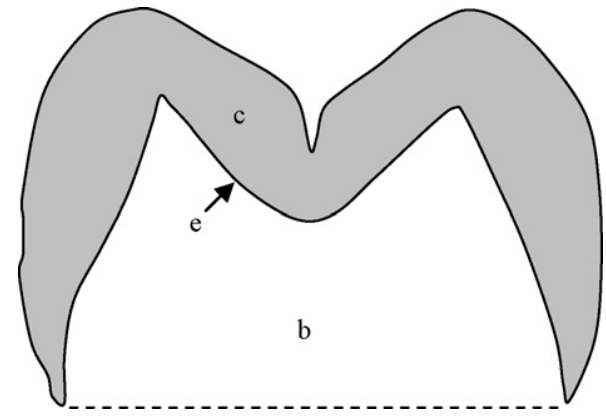

Fig. 3 - Enamel area measurements. $c$ = area of enamel cap; $b=$ area of dentine; $e=$ length of the enamel-dentine junction.

\subsection{Measurements}

Average enamel thickness was calculated as, the area of the enamel cap (c) divided by the length of the enamel-dentine junction (e) (Fig. 3). This gave the average straight-line thickness between the enamel-dentine junction (EDJ) and the outer enamel surface. Fourteen linear measurements were recorded from images of the mesial and distal sections (Table 1 and Fig. 4). Measurements were taken as perpendicular as possible to the occlusal enamel surface and the enameldentine junction. ${ }^{15}$ If undulations in local topography of the EDJ resembled examples given by Suwa and $\mathrm{Kono}^{51}$ (see their Fig. 2), these sections were excluded from the study.

\subsection{Statistical procedures}

Inferential statistical analyses were conducted on AET and the linear measurements. A one-way analysis of variance analysis (ANOVA) was used to identify differences in AET amongst the molars. Equality of variance of each molar group was checked with Levene's homogeneity-of-variance test. Tukey's-b post hoc test was selected to localize significant differences between the molar groups. The significance level was set at $p \leq 0.05$. All statistical tests were conducted with SPSS 15.0.

Differences between the linear enamel measurements were sought in three ways; within cusps; between the cusps of each molar; between molars. Paired-samples t-tests were used to identify significant differences in linear enamel measurements within and between cusps. The test assumption, that the

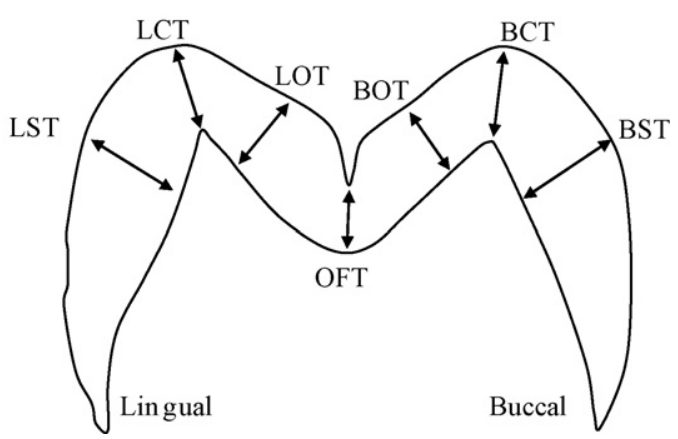

Fig. 4 - Linear enamel measurements. (Definitons are in Table 1). 
Table 2 - Area and AET measurements for the mesial and distal sections.

\begin{tabular}{|c|c|c|c|c|c|c|c|c|c|c|}
\hline & \multicolumn{5}{|c|}{ Mesial } & \multicolumn{5}{|c|}{ Distal } \\
\hline & $a$ & $b$ & $c$ & $e$ & AET & $a$ & $b$ & $C$ & e & AET \\
\hline \multicolumn{11}{|l|}{$d m 1$} \\
\hline X & 29.70 & 23.48 & 6.22 & 14.82 & 0.42 & 21.73 & 16.02 & 5.71 & 12.98 & 0.44 \\
\hline Min & 22.88 & 18.18 & 4.70 & 13.40 & 0.35 & 16.81 & 12.80 & 4.01 & 10.90 & 0.37 \\
\hline Max & 39.06 & 30.25 & 8.81 & 16.16 & 0.55 & 30.62 & 22.52 & 8.10 & 15.25 & 0.53 \\
\hline $\pm 1 \mathrm{sd}$ & 3.65 & 3.01 & 0.97 & 0.81 & 0.05 & 3.54 & 3.07 & 0.90 & 1.06 & 0.05 \\
\hline \multicolumn{11}{|l|}{$d m 2$} \\
\hline X & 38.79 & 28.29 & 10.50 & 16.88 & 0.62 & 39.27 & 28.48 & 10.79 & 17.01 & 0.63 \\
\hline Min & 26.81 & 20.07 & 6.74 & 13.77 & 0.49 & 28.59 & 21.56 & 7.03 & 14.09 & 0.50 \\
\hline Max & 51.16 & 35.11 & 16.05 & 19.01 & 0.84 & 53.34 & 36.40 & 16.94 & 20.27 & 0.84 \\
\hline $\pm 1 s d$ & 4.70 & 3.74 & 1.95 & 1.33 & 0.11 & 4.68 & 3.51 & 1.76 & 1.55 & 0.07 \\
\hline \multicolumn{11}{|l|}{ M1 } \\
\hline X & 57.28 & 38.07 & 19.21 & 19.79 & 0.97 & 55.94 & 35.09 & 20.85 & 18.98 & 1.10 \\
\hline Min & 43.12 & 27.54 & 15.58 & 17.16 & 0.90 & 41.45 & 25.15 & 16.30 & 15.32 & 1.06 \\
\hline Max & 73.67 & 47.69 & 25.98 & 22.13 & 1.17 & 72.28 & 45.82 & 26.46 & 21.35 & 1.24 \\
\hline $\pm 1 \mathrm{sd}$ & 6.88 & 5.50 & 2.65 & 1.53 & 0.45 & 6.63 & 5.11 & 2.55 & 1.40 & 0.45 \\
\hline
\end{tabular}

$a$, total area of the tooth crown section (' $b$ ' and ' $c$ ' summed) in $\mathrm{mm}^{2} . b$, area of dentine and pulp enclosed by the dentine-enamel junction and a straight line between the buccal and lingual cervical margins in $\mathrm{mm}^{2}$ (see Fig. 3). c, Area of the sectioned enamel cap in $\mathrm{mm}^{2}$ (Fig. 3).e, Length of the enamel-dentine junction in $\mathrm{mm}$. AET, average enamel thickness in $\mathrm{mm}$.

differences calculated for each pair have a normal distribution, ${ }^{54}$ was checked with a Kolmogorov-Smirnov goodness-offit-test.

Following this a discriminant function analysis (DFA) was chosen to assess how the linear measurements interacted and distinguished between the molars. Data screening for this multivariate analysis followed Tabachnick and Fidell. ${ }^{55}$ A DFA assumes that the variables (i.e., the linear enamel measurements) will have a multivariate normal distribution and the within-group variance-covariance matrix will be equal across the groups. A DFA is also sensitive to multivariate outliers. Multivariate normality and homogeneity of the variancecovariance matrices was assessed through Box's $M$ test. Multivariate outliers were identified in the data for the mesial sections of $d m 1$ and $d m 2$ by examining the Mahalanobis Measure of Distance given in the SPSS print out for a DFA. The influence of these outliers was reduced by conducting a log transformation on the data from the $\mathrm{dm} 1$ mesial sections, and a square root transformation on the data from the $\mathrm{dm} 2 \mathrm{mesial}$ sections. ${ }^{55}$ The DFA was then conducted on the transformed data for these variables. The overall success of the DFA was evaluated through eigen and canonical correlation values, whilst the structure matrix and values for Wilks lambda were used to gauge the contribution of each measurement to the discrimination.

\section{Results}

\subsection{Average enamel thickness between molars}

Comparisons of AET between the mesial sections, and then the distal sections, showed significant differences along the molar row. Tukey's-b test indicated that the AET of dm1 was less than $d \mathrm{~m} 2$, and that $d \mathrm{~m} 2$ was less than M1. Area and AET measurements are shown in Table 2. Inferential statistics and Levenes homogeneity-of-variance test are given in Table 3.
Box plots illustrating the differences along the molar row are shown in Fig. 5.

\subsection{Comparing linear enamel thickness measurements within cusps of each molar}

Comparisons within each cusp indicated that for each molar type, enamel was significantly thicker on the outer surface of all cusps, compared to their tips and occlusal slopes. Enamel was thicker on the occlusal slopes compared to their tips on all $\mathrm{dm} 1$ cusps, as well as the $\mathrm{dm} 2$ buccal cusps. No differences emerged between these surfaces on M1. Descriptive statistics for all linear enamel measurement are given in Table 4 . The results for the Kolmogorov-Smirnov normality test is given in Table 5. Inferential statistics are given in Table 6.

\subsection{Comparing linear enamel thickness measurements between cusps of each molar}

Comparisons between buccal vs. lingual cusp analogues showed that for each molar type, enamel was significantly thicker on the outer surface of the protoconid and hypoconid compared to the outer surface of the metaconid and entoconid

Table 3 - Comparing AET between the molars.

\begin{tabular}{|c|c|c|c|c|c|c|}
\hline & \multicolumn{3}{|c|}{ Mesial $^{a, b}$} & \multicolumn{3}{|c|}{ Distal $^{\mathrm{c}, \mathrm{d}}$} \\
\hline & $f$ & df & $p$ & $f$ & df & $p$ \\
\hline AET & 41.275 & 2 & $0.000^{*}$ & 57.765 & 2 & $0.000^{*}$ \\
\hline \multicolumn{7}{|c|}{ 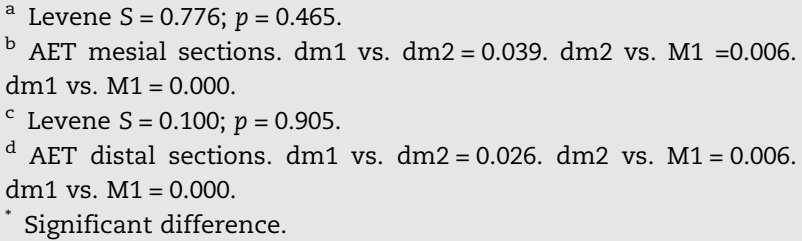 } \\
\hline
\end{tabular}



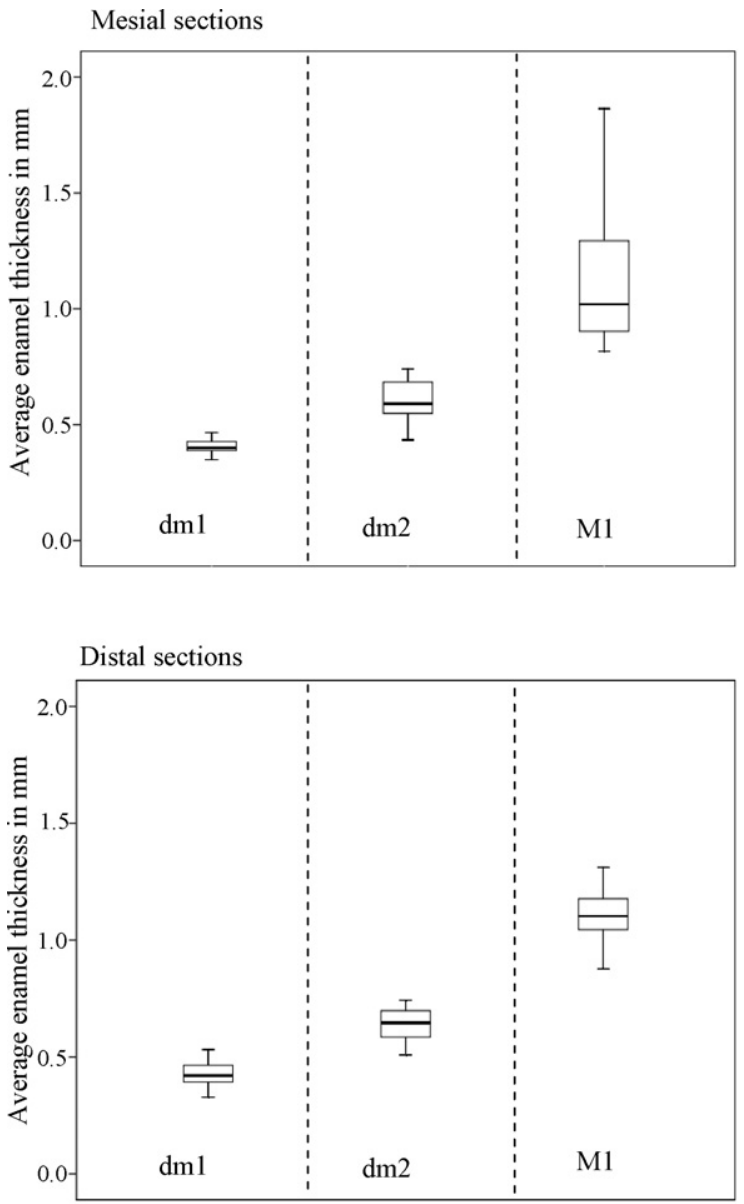

Fig. 5 - Box plots for AET.

respectively, except for the dm2 distal sections. For both deciduous molars, enamel was thinner on the tips of the hypoconid compared to the entoconid. The hypoconid occlusal slopes on both $\mathrm{dm} 1$ and M1 were thicker compared to the entoconid.
Table 5 - Normality test: difference between means for paired samples.

\begin{tabular}{|c|c|c|c|c|c|c|}
\hline \multirow[t]{2}{*}{ Cusp } & \multicolumn{2}{|c|}{$\mathrm{dm} 1$} & \multicolumn{2}{|c|}{$\mathrm{dm} 2$} & \multicolumn{2}{|c|}{ M1 } \\
\hline & z & $p$ & $z$ & $p$ & $\mathrm{z}$ & $p$ \\
\hline \multicolumn{7}{|l|}{ Prd } \\
\hline BST vs. BCT & 0.694 & 0.720 & 0.789 & 0.562 & 0.591 & 0.876 \\
\hline BST vs. BOT & 0.544 & 0.929 & 0.815 & 0.520 & 0.732 & 0.658 \\
\hline BCT vs. BOT & 0.811 & 0.527 & 0.811 & 0.526 & 0.503 & 0.962 \\
\hline \multicolumn{7}{|l|}{ Med } \\
\hline LST vs. LCT & 0.615 & 0.844 & 0.787 & 0.565 & 0.653 & 0.787 \\
\hline LST vs. LOT & 0.457 & 0.985 & 0.795 & 0.553 & 0.454 & 0.986 \\
\hline LCT vs. LOT & 0.516 & 0.953 & 0.429 & 0.993 & 0.940 & 0.339 \\
\hline \multicolumn{7}{|l|}{ Hyd } \\
\hline BST vs. BCT & 0.707 & 0.699 & 0.530 & 0.942 & 0.657 & 0.781 \\
\hline BST vs. BOT & 0.849 & 0.466 & 0.793 & 0.555 & 0.381 & 0.999 \\
\hline BCT vs. BOT & 0.440 & 0.990 & 0.550 & 0.923 & 0.677 & 0.748 \\
\hline \multicolumn{7}{|l|}{ End } \\
\hline LST vs. LCT & 0.609 & 0.851 & 0.550 & 0.922 & 0.627 & 0.827 \\
\hline LST vs. LOT & 0.849 & 0.406 & 0.495 & 0.967 & 0.418 & 0.995 \\
\hline LCT vs. LOT & 0.518 & 0.952 & 0.511 & 0.955 & 0.601 & 0.863 \\
\hline
\end{tabular}

Comparisons between mesial vs. distal cusp analogues revealed that the M1 hypoconid had thicker enamel at all locations compared to the protoconid, whilst the entoconid had thicker cusp tip and occlusal slope enamel compared to the metaconid. The dm 1 hypoconid had thicker occlusal slopes compared to the protoconid, whilst the entoconid had thicker cusp tips compared to the metaconid. No differences emerged between the $\mathrm{dm} 2$ mesial and distal cusp analogues. The results for the Kolmogorov-Smirnov normality test are given in Table 7. Inferential statistics are given in Table 8.

\subsection{Comparing $d m 1$ and dm2 linear enamel thickness measurements using a DFA}

A discriminant function analysis of the deciduous molars produced one function with an $\mathrm{X}^{2}$ (6) of 47.702, $p=0.000$, for the mesial sections, and another with an $X^{2}(6)$ of 70.254 , $p=0.000$, for the distal sections. The $p$ value indicated that the

Table 4 - Descriptive statistics for linear enamel thickness measurements (in $\mathrm{mm}$ ).

\begin{tabular}{|c|c|c|c|c|c|c|c|c|c|c|c|c|c|c|}
\hline & \multicolumn{7}{|c|}{ Mesial } & \multicolumn{7}{|c|}{ Distal } \\
\hline & BST & BCT & BOT & OFT & LOT & LCT & LST & BST & BCT & BOT & OFT & LOT & LCT & LST \\
\hline \multicolumn{15}{|l|}{$d m 1$} \\
\hline$X$ & 0.64 & 0.30 & 0.45 & 0.47 & 0.46 & 0.29 & 0.51 & 0.62 & 0.30 & 0.55 & 0.44 & 0.45 & 0.39 & 0.52 \\
\hline Min & 0.48 & 0.11 & 0.33 & 0.31 & 0.27 & 0.16 & 0.32 & 0.49 & 0.12 & 0.41 & 0.25 & 0.19 & 0.14 & 0.32 \\
\hline Max & 0.82 & 0.64 & 0.63 & 0.66 & 0.67 & 0.53 & 0.67 & 0.88 & 0.48 & 0.68 & 0.58 & 0.64 & 0.64 & 0.72 \\
\hline $\pm 1 \mathrm{sd}$ & 0.09 & 0.11 & 0.07 & 0.09 & 0.09 & 0.10 & 0.08 & 0.09 & 0.10 & 0.08 & 0.09 & 0.12 & 0.14 & 0.09 \\
\hline \multicolumn{15}{|l|}{$d m 2$} \\
\hline$X$ & 0.98 & 0.45 & 0.66 & 0.57 & 0.63 & 0.60 & 0.92 & 0.94 & 0.47 & 0.68 & 0.50 & 0.63 & 0.62 & 0.90 \\
\hline Min & 0.63 & 0.20 & 0.50 & 0.32 & 0.51 & 0.20 & 0.66 & 0.75 & 0.17 & 0.38 & 0.31 & 0.46 & 0.28 & 0.62 \\
\hline Max & 1.27 & 0.80 & 0.83 & 0.83 & 0.71 & 1.01 & 1.12 & 1.13 & 0.81 & 0.87 & 0.72 & 0.82 & 0.99 & 1.02 \\
\hline $\pm 1 \mathrm{sd}$ & 0.15 & 0.12 & 0.11 & 0.14 & 0.10 & 0.09 & 0.11 & 0.10 & 0.11 & 0.14 & 0.08 & 0.16 & 0.12 & 0.11 \\
\hline \multicolumn{15}{|l|}{ M1 } \\
\hline$X$ & 1.56 & 1.16 & 1.19 & 0.87 & 1.13 & 1.13 & 1.43 & 1.67 & 1.30 & 1.36 & 0.80 & 1.23 & 1.26 & 1.46 \\
\hline Min & 1.30 & 0.67 & 0.84 & 0.11 & 0.84 & 0.80 & 1.16 & 1.31 & 0.52 & 0.99 & 0.28 & 0.78 & 0.56 & 0.96 \\
\hline Max & 2.19 & 1.69 & 2.05 & 1.37 & 1.60 & 1.57 & 1.88 & 2.07 & 1.78 & 1.80 & 1.28 & 1.78 & 1.74 & 1.99 \\
\hline $\pm 1 \mathrm{sd}$ & 0.19 & 0.26 & 0.27 & 0.31 & 0.22 & 0.21 & 0.19 & 0.18 & 0.18 & 0.23 & 0.25 & 0.24 & 0.25 & 0.26 \\
\hline
\end{tabular}


Table 6 - Comparing enamel thickness measurements within the cusps.

\begin{tabular}{|c|c|c|c|c|c|c|c|c|c|}
\hline \multirow[t]{2}{*}{ Cusp } & \multicolumn{3}{|c|}{$\mathrm{dm} 1$} & \multicolumn{3}{|c|}{$\mathrm{dm} 2$} & \multicolumn{3}{|c|}{ M1 } \\
\hline & $t$ & $\mathrm{df}$ & $p$ & $t$ & $\mathrm{df}$ & $p$ & $t$ & $\mathrm{df}$ & $p$ \\
\hline \multicolumn{10}{|l|}{ Prd } \\
\hline BST vs. BCT & 8.330 & 15 & $0.000^{*}$ & 9.871 & 19 & $0.000^{*}$ & 6.919 & 24 & $0.000^{\circ}$ \\
\hline BST vs. BOT & 12.007 & 20 & $0.000^{*}$ & 7.793 & 19 & $0.000^{*}$ & 11.299 & 24 & $0.000^{\circ}$ \\
\hline BCT vs. BOT & -3.779 & 15 & $0.002^{*}$ & -5.312 & 19 & $0.000^{\circ}$ & -0.574 & 24 & 0.571 \\
\hline \multicolumn{10}{|l|}{ Med } \\
\hline LST vs. LCT & -7.737 & 20 & $0.000^{*}$ & -6.340 & 19 & $0.000^{*}$ & 6.581 & 24 & $0.000^{\circ}$ \\
\hline LST vs. LOT & 3.301 & 20 & $0.001^{*}$ & -10.620 & 19 & $0.000^{*}$ & 9.108 & 24 & $0.000^{\circ}$ \\
\hline LCT vs. LOT & -5.848 & 20 & $0.000^{*}$ & 0.470 & 19 & 0.644 & -0.604 & 24 & 0.551 \\
\hline \multicolumn{10}{|l|}{ Hyd } \\
\hline BST vs. BCT & 11.355 & 17 & $0.000^{*}$ & 13.343 & 19 & $0.000^{*}$ & 6.827 & 24 & $0.000^{\circ}$ \\
\hline BST vs. BOT & 3.685 & 20 & $0.001^{*}$ & 9.109 & 19 & $0.000^{*}$ & 13.252 & 24 & $0.000^{\circ}$ \\
\hline BCT vs. BOT & -8.821 & 20 & $0.000^{*}$ & -7.113 & 19 & $0.000^{*}$ & -1.203 & 24 & 0.240 \\
\hline \multicolumn{10}{|l|}{ End } \\
\hline LST vs. LCT & -3.423 & 20 & $0.003^{*}$ & 5.739 & 19 & $0.000^{*}$ & 3.691 & 24 & $0.000^{\circ}$ \\
\hline LST vs. LOT & 2.426 & 20 & $0.025^{*}$ & 10.040 & 19 & $0.000^{*}$ & 7.035 & 24 & $0.000^{\circ}$ \\
\hline LCT vs. LOT & -2.216 & 20 & $0.039^{*}$ & -0.086 & 19 & 0.932 & 0.711 & 24 & 0.483 \\
\hline
\end{tabular}

mean of each function was not equal across molars. The structure matrix (Table 9) showed that in each analysis, measurements from the outer surfaces of the lingual cusps (measurement LST) contributed the most to each function, followed by the outer surfaces of the buccal cusp (measurement

Table 7 - Normality test: difference between means for paired samples tests.

\begin{tabular}{|c|c|c|c|c|c|c|}
\hline \multirow[t]{2}{*}{ Cusp } & \multicolumn{2}{|c|}{$\mathrm{dm} 1$} & \multicolumn{2}{|c|}{$\mathrm{dm} 2$} & \multicolumn{2}{|c|}{ M1 } \\
\hline & $\mathrm{Z}$ & $p$ & $\mathrm{Z}$ & $p$ & $Z$ & $p$ \\
\hline \multicolumn{7}{|l|}{ Prd us. Med } \\
\hline BST vs. LST & 0.795 & 0.552 & 0.547 & 0.926 & 0.384 & 0.998 \\
\hline BCT vs. LCT & 0.508 & 0.959 & 0.474 & 0.978 & 0.866 & 0.441 \\
\hline BOT vs. LOT & 0.445 & 0.987 & 0.753 & 0.623 & 0.461 & 0.984 \\
\hline \multicolumn{7}{|l|}{ Prd us. Hyd } \\
\hline BST vs. BST & 0.667 & 0.765 & 0.807 & 0.533 & 0.678 & 0.747 \\
\hline BCT vs. BCT & 0.560 & 0.912 & 0.568 & 0.904 & 0.561 & 0.911 \\
\hline BOT vs. BOT & 0.720 & 0.677 & 0.504 & 0.961 & 0.566 & 0.906 \\
\hline \multicolumn{7}{|l|}{ Prd us. End } \\
\hline BST vs. LST & 0.464 & 0.983 & 0.524 & 0.947 & 0.644 & 0.801 \\
\hline BCT vs. LCT & 0.943 & 0.336 & 0.581 & 0.888 & 0.585 & 0.884 \\
\hline BOT vs. LOT & 0.655 & 0.784 & 0.506 & 0.960 & 0.426 & 0.993 \\
\hline \multicolumn{7}{|l|}{ Hyd us. End } \\
\hline BST vs. LST & 0.351 & 1.000 & 0.881 & 0.419 & 0.836 & 0.486 \\
\hline BCT vs. LCT & 0.412 & 0.996 & 0.453 & 0.986 & 0.479 & 0.976 \\
\hline BOT vs. LOT & 0.621 & 0.835 & 0.683 & 0.739 & 0.650 & 0.793 \\
\hline \multicolumn{7}{|l|}{ Hyd us. Med } \\
\hline BST vs. LST & 0.801 & 0.542 & 0.975 & 0.298 & 0.977 & 0.295 \\
\hline BCT vs. LCT & 0.506 & 0.960 & 0.512 & 0.956 & 0.547 & 0.926 \\
\hline BOT vs. LOT & 0.460 & 0.984 & 0.927 & 0.357 & 0.800 & 0.544 \\
\hline \multicolumn{7}{|l|}{ End us. Med } \\
\hline LST vs. LST & 0.487 & 0.972 & 1.021 & 0.248 & 0.472 & 0.979 \\
\hline LCT vs. LCT & 0.479 & 0.976 & 0.496 & 0.966 & 0.577 & 0.894 \\
\hline LOT vs. LOT & 0.792 & 0.558 & 0.368 & 0.999 & 0.672 & 0.758 \\
\hline \multicolumn{7}{|c|}{ Occlusal fovea } \\
\hline OFT vs. OFT & 0.699 & 0.713 & 0.631 & 0.821 & 0.452 & 0.987 \\
\hline
\end{tabular}

BST). The high measures of variance for the function created from the mesial measurements (eigen value ' $E$ ' = 3.904; canonical correlation ' $U$ ' $=0.892$ ) indicates good discrimination between the dm1 and dm2. This is confirmed by the significant difference between the mean values of each measurement when grouped by molar type (except for the protoconid cusp tips). Discrimination between the distal sections of the two deciduous molars was relatively more successful $(E=6.443 ; U=0.930)$. This is also suggested by the significance test, which showed that the six measurements differed from each other. Box's $M$ test for multivariate normality and homogeneity of the variancecovariance matrices are shown in Table 9.

\subsection{Comparing dm2 and M1 linear enamel thickness measurements using a DFA}

One discriminant function was calculated with an $X^{2}(6)$ of 63.595, $P=0.000$, for the mesial sections, and another with an $X^{2}$ (6) of $90.613, P=0.000$, for the distal sections. The outer surfaces of the buccal cusps (BST) contributed most to the discrimination between the teeth followed by the tips (Table 10). The measures of variance for each function indicated that discrimination between these molars was much greater for the distal sections $(E=7.649 ; U=0.940)$, compared to the discrimination between the mesial sections $(E=3.903$; $U=0.832)$. This latter interpretation is supported by the tables of raw mean values (Table 4), which showed a greater increase in enamel thickness across the distal sections (excluding OFT). Box's $M$ test for multivariate normality and homogeneity of the variance-covariance matrices are shown in Table 10.

\section{Discussion}

\subsection{Enamel thickness comparisons along the molar row}

The increase in AET between the mesial sections of the deciduous molars lends support to results reported for relative 
Table 8 - Comparing enamel thickness measurements between the cusps.

\begin{tabular}{|c|c|c|c|c|c|c|c|c|c|}
\hline \multirow[t]{2}{*}{ Cusp } & \multicolumn{3}{|c|}{$\mathrm{dm} 1$} & \multicolumn{3}{|c|}{$\mathrm{dm} 2$} & \multicolumn{3}{|c|}{ M1 } \\
\hline & $t$ & $\mathrm{df}$ & $p$ & $t$ & $\mathrm{df}$ & $p$ & $t$ & df & $p$ \\
\hline \multicolumn{10}{|l|}{ Prd us. Med } \\
\hline BST vs. LST & 5.850 & 20 & $0.000^{*}$ & -2.400 & 19 & $0.033^{*}$ & -3.620 & 24 & $0.001^{*}$ \\
\hline BCT vs. LCT & 0.675 & 15 & 0.511 & -3.014 & 19 & $0.007^{*}$ & -0.556 & 24 & 0.583 \\
\hline BOT vs. LOT & -0.367 & 20 & 0.718 & -1.197 & 19 & 0.246 & -1.117 & 24 & 0.274 \\
\hline \multicolumn{10}{|l|}{ Prd us. Hyd } \\
\hline BST vs. BST & -0.209 & 20 & 0.864 & -0.955 & 19 & 0.352 & -3.061 & 23 & $0.005^{*}$ \\
\hline BCT vs. BCT & 0.370 & 15 & 0.716 & -2.242 & 19 & 0.811 & -3.177 & 23 & $0.004^{*}$ \\
\hline BOT vs. BOT & -5.594 & 20 & $0.000^{*}$ & -0.662 & 19 & 0.516 & -3.770 & 23 & $0.001^{*}$ \\
\hline \multicolumn{10}{|l|}{ Prd us. End } \\
\hline BST vs. LST & -2.898 & 20 & $0.009^{*}$ & -3.325 & 19 & $0.004^{*}$ & 1.088 & 23 & 0.301 \\
\hline BCT vs. LCT & -2.488 & 15 & $0.025^{*}$ & -3.314 & 19 & $0.004^{*}$ & -2.023 & 23 & 0.053 \\
\hline BOT vs. LOT & 0.397 & 20 & 0.695 & -1.160 & 19 & 0.260 & -0.931 & 23 & 0.360 \\
\hline \multicolumn{10}{|l|}{ Hyd us. End } \\
\hline BST vs. LST & 5.159 & 20 & $0.000^{*}$ & -2.009 & 19 & 0.053 & -5.890 & 24 & $0.000^{\circ}$ \\
\hline BCT vs. LCT & -2.926 & 20 & $0.008^{*}$ & -3.286 & 19 & $0.004^{*}$ & -1.244 & 24 & 0.225 \\
\hline BOT vs. LOT & 3.788 & 20 & $0.001^{*}$ & -1.550 & 19 & 0.138 & -3.905 & 24 & $0.001^{*}$ \\
\hline \multicolumn{10}{|l|}{ Hyd us. Med } \\
\hline BST vs. LST & -7.212 & 20 & $0.000^{*}$ & -1.403 & 19 & 0.191 & -7.623 & 23 & $0.000^{*}$ \\
\hline BCT vs. LCT & 0.886 & 20 & 0.386 & -2.347 & 19 & $0.030^{*}$ & -3.277 & 23 & $0.003^{*}$ \\
\hline BOT vs. LOT & 7.660 & 20 & $0.000^{*}$ & -1.945 & 19 & 0.067 & -5.977 & 23 & $0.000^{*}$ \\
\hline \multicolumn{10}{|l|}{ End us. Med } \\
\hline LST vs. LST & 0.194 & 20 & 0.967 & -0.383 & 19 & 0.706 & -0.461 & 23 & 0.649 \\
\hline LCT vs. LCT & 4.882 & 20 & $0.000^{*}$ & 0.345 & 19 & 0.743 & -3.001 & 23 & $0.009^{*}$ \\
\hline LOT vs. LOT & 0.202 & 20 & 0.901 & -0.044 & 19 & 0.965 & -2.529 & 23 & $0.018^{*}$ \\
\hline \multicolumn{10}{|c|}{ Occlusal fovea } \\
\hline OFT vs. OFT & -2.703 & 20 & 0.014 & 1.983 & 19 & 0.062 & -0.707 & 23 & 0.445 \\
\hline
\end{tabular}

" Significant difference.

Table 9 - Structure matrix for the DFA of dm1 vs. dm2.

\begin{tabular}{|c|c|c|c|c|c|c|c|}
\hline & \multicolumn{3}{|c|}{ Mesial $^{\mathrm{a}}$} & & \multicolumn{3}{|c|}{ Distal $^{\mathrm{e}}$} \\
\hline & Structure ${ }^{b}$ & $W^{c}$ & $p^{\mathrm{d}}$ & & Structure & W & $p$ \\
\hline LST & 0.843 & 0.265 & $0.000^{*}$ & LST & 0.895 & 0.162 & $0.000^{\circ}$ \\
\hline BST & 0.634 & 0.389 & $0.000^{*}$ & BST & 0.646 & 0.271 & $0.000^{*}$ \\
\hline LCT & 0.626 & 0.395 & $0.000^{*}$ & BCT & 0.321 & 0.601 & $0.000^{* *}$ \\
\hline ВОт & 0.522 & 0.484 & $0.000^{*}$ & LCT & 0.284 & 0.658 & $0.000^{\circ}$ \\
\hline LOT & 0.494 & 0.512 & $0.000^{*}$ & BOT & 0.239 & 0.731 & $0.001^{*}$ \\
\hline BCT & 0.207 & 0.860 & 0.070 & LOT & 0.229 & 0.747 & $0.001^{*}$ \\
\hline
\end{tabular}

a Box $M=36.103 ; p=0.110$

${ }^{\mathrm{b}}$ Correlation between the enamel thickness measurements and the discriminant function. Higher values have a greater correlation.

c Wilks Lambda. The potential contribution of each measurement to the discriminating power of the function. Lower values have a greater potential.

d $T$ test of each measurement grouped by molar type.

e Box $M=20.692 ; p=0.705$

Significant difference.

and linear enamel thickness. ${ }^{42,43}$ Data from the distal sections replicates these findings. Increased AET in dm2 was facilitated by a larger enamel cap area compared to dm1. This, together with a larger dentine area resulted in comparatively larger $\mathrm{dm} 2$ crown sections. A posterior increase in deciduous molar size has previously been reported from measurements of whole tooth crowns. ${ }^{42,56,57}$ Data presented in this study indicate that this is due to an increase in both the enamel and dentine component of the tooth.

Linear measurements of enamel thickness did not discriminate between the molar types equally. The greatest proportional increase in linear enamel thickness from $\mathrm{dm} 1$ to dm2 occurred on the outer surfaces of the lingual cusps (Table 9). This was accompanied by an increased similarity in the enamel thickness measurements upon (not between) the $\mathrm{dm} 2$ lingual cusps (Table 6). The dm2 lingual cusp tips became thicker, and no longer differed when compared to their occlusal slopes, unlike the dm2 buccal cusps.

In contrast to the change in enamel thickness between the deciduous molars, the greatest proportional increase in linear enamel thickness between $\mathrm{dm} 2$ and M1 occurred between the outer surfaces of the buccal cusps. This is seen most clearly in 
Table 10 - Structure matrix for the DFA of dm2 vs. M1.

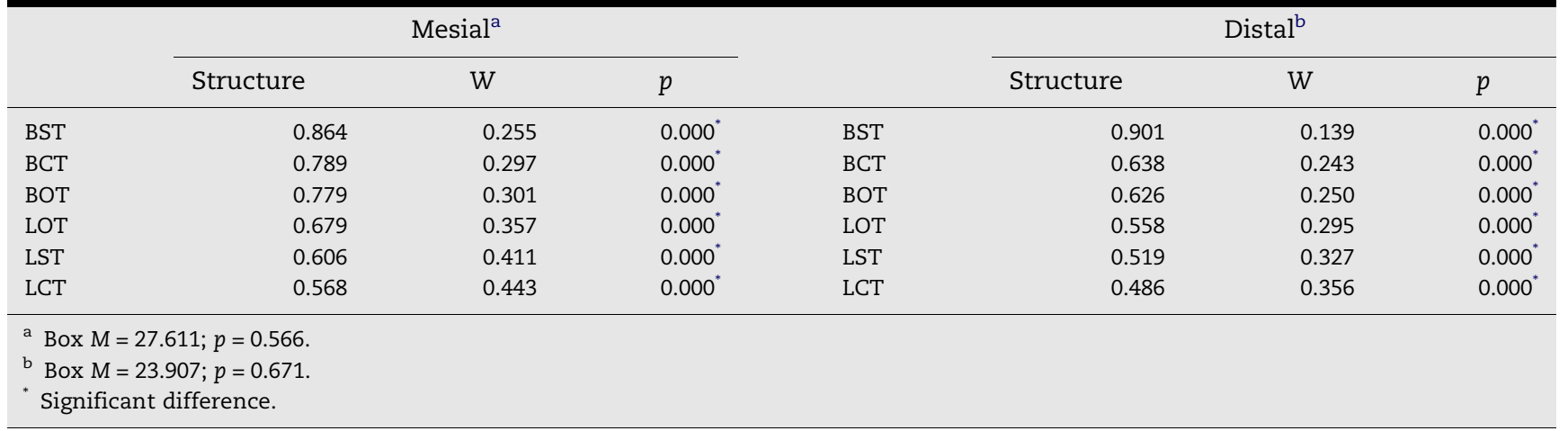

the discrimination between the distal sections (Table 10), which was also influenced by variations in enamel thickness across the M1 mesial-distal surface (discussed below). This pattern was mirrored again, by an increased similarity in the enamel thickness measurements upon the molar cusps, whereby the M1 buccal cusp tips became thicker, and did not differ when compared to their occlusal slope (Table 6). Therefore, whilst AET increased posteriorly between deciduous and permanent first molars, the increase in linear thickness was not the same for all cusps. From dm 1 to dm 2 the greatest proportional increase in enamel thickness was on the outside of the lingual cusps, with a simultaneous increased thickness at the lingual cusp tip. From dm2 to M1, the greatest increase was on the outside of the buccal cusps, with a simultaneous increased thickness at the buccal cusp tip.

\subsection{Functional implications from enamel thickness along molar row}

Arguing that the posterior increase in deciduous enamel thickness reflects increased bite force is difficult. Studies on permanent dentition indicate that increased enamel thickness along the molar row does not always correlate with increased bite force. Experimental data for bite force in children is limited. A morphological interpretation can be evoked, but it is not the same as the model applied to permanent teeth. Unlike the findings reported for permanent molars, there was no posterior reduction in the dentine area, or tooth size, when dm1 was compared to dm2. Instead, both the dentine and enamel components increased in $\mathrm{dm} 2$ leading to a larger tooth.

An alternative explanation is to extrapolate the interpretative model from studies of permanent molars and consider the change in deciduous enamel thickness in terms of the direction of the force, rather than the magnitude. In permanent molars, increased enamel thickness together with increased symmetry between the buccal and lingual cusp tips of posterior maxillary molars might provide a stronger and more evenly distributed surface for increased crushing and grinding, due to a reduction in the lateral excursion of the mandible (and less shearing) towards the temporomandibular joint. ${ }^{15,41}$ The pattern of enamel thickness reported for the deciduous molars can be related to a similar but not identical functional model. Average enamel thickness increased posteriorly between the molars in this study. Similarities in the enamel thickness measurements upon the lingual molar cusps also increased posteriorly, when the cusps tips were compared to their occlusal slopes in dm2. With this in mind, the relatively strengthened lingual cusp (proportionally thicker outer surface, increased similarity between the cusp tip and slope), which was not seen in the dm1, may provide a tooth surface that is more suited to crushing and grinding, like the situation posed for maxillary molars. More crushing and grinding on $\mathrm{dm} 2$ would also be facilitated by the more even mesial-distal enamel distribution.

Increased similarities in enamel thickness measurements upon the M1 cusps (not between), compared to dm2 may indicate one anterior-posterior trend across the three molar types. Though speculative, perhaps this in some way reflects the short period in which the three molar types have erupted and are present together in the jaw. Mainly though, differences between dm2 and M1 are dominated by the thick outer buccal permanent enamel (discussed further below), which Grine $^{22}$ indicates may provide a buttressing effect to prolong functional crown life.

\subsection{Buccal-lingual, mesial-distal comparisons of enamel thickness}

The M1 showed marked trends in enamel distribution. Enamel was thicker on the protoconid outer surface compared to the metaconid, ${ }^{22}$ and the M1 distal cusps followed this buccallingual trend. Linear measurements of M1 enamel thickness, as well as AET ( $t=-4.917, \mathrm{df}=24, p=0.000)$, increased when the distal sections were compared to the mesial sections, and the hypoconid had the thickest enamel overall. Increased AET in distal M1 sections has been reported previously for Pan and Pongo $^{7}$, whilst others have identified thick hypoconid enamel on human permanent molars. ${ }^{16}$ In this study, the thicker distal AET was due to a slight increase in the area of the enamel cap, which was accompanied by a decrease in the dentine area, which led to a slight reduction in overall size of the section (Table 2).

Some of the mesial-distal M1 patterns of enamel thickness are not easily explained entirely from a functional perspective. For instance, mesial enamel was thin at the cusp tips. Others have reported thin enamel at the cusp tip of the M1 protoconid. ${ }^{16,22,27,51}$ It may be that developmental constraints can affect enamel thickness patterns. For instance, Martin ${ }^{58}$ proposed that differences in enamel thickness between molars might reflect development. For permanent first molars, there are indications that aspects of enamel development and thickness can be associated. Human cusp tip enamel thickness 
is positively correlated with appositional formation time. ${ }^{45,59}$ Mandibular M1 buccal cusp enamel in Pan is, on average, thicker and takes longer to form compared to the lingual cusp. ${ }^{60}$ Similar indications of this association have been reported along the tooth row. Increased enamel thickness in human distal permanent molars seems to be facilitated by slightly increased crown formation times (see Reid et al. ${ }^{52}$ specimen T49). Therefore, it would seem likely that, to some extent, differences in enamel thickness upon a molar may sometimes reflect an underlying developmental constraint.

Buccal lingual directional trends in dm2 enamel distribution were not as clear as those seen on the M1. Differences between the dm2 outer surfaces especially, were far less pronounced, which was unlike the permanent tooth. This was mainly responsible for the changing pattern in linear enamel thickness between these tooth types. Neither were there any significant mesial-distal differences in AET between the dm2 sections $(t=-0.316, \mathrm{df}=18, p=0.756)$, or even the measurements of linear enamel thickness (Table 4).

The average total area of the $\mathrm{dm} 1$ mesial crown sections was greater compared to the distal sections. This difference was due to the prominent bulge called the molar tubercle of Zuckerkandl, located on the mesiobuccal crown. ${ }^{61}$ Data from this study shows that the tubercle leads to increased dentine, rather than a significantly increased enamel component. Others have shown that the shape of the EDJ can determine the morphology of the outer enamel surface. ${ }^{62,63}$ Whilst phylogenetic studies have discussed the relative contributions of molar dentine and enamel proportions in the genus Homo. ${ }^{48}$ Future phylogenetic studies may profitable explore dentine proportions when they consider dental traits at the outer enamel surface.

\section{Conclusions}

1. Enamel cap and dentine area increased from $\operatorname{dm} 1$ to $\mathrm{M} 1$.

2. Similarities in cusp enamel thickness measurements increased from $\mathrm{dm} 1$ to $\mathrm{M} 1$.

3. Changes in linear enamel thickness were not constant along the molar row. Differences between the deciduous molars were greatest on the outside surface of the lingual cusps. Differences between dm2 and M1 were greatest on the outside surface of the buccal cusps.

4. Mesial-distal changes in enamel cap and dentine area occurred on M1 and dm1 respectively, but not on dm2.

\section{Funding}

None.

\section{Conflict of interest}

None declared.

\section{Ethical approval}

Not required.

\section{Acknowledgements}

The author thanks four anonymous reviewers and Gabriele Macho for comments on the manuscript. The Powell Cotton Museum, Hull and East Riding Museum, The National Museums of Scotland, The Marischal Museum, and the University of Kent facilitated access to samples in their care.

\section{Appendix A. Supplementary data}

Supplementary data associated with this article can be found, in the online version, at doi:10.1016/j.archoralbio.2009.11.014.

\section{R E F E R E N C E S}

1. Boyde A. The structure and development of mammalian tissue. University of London: PhD Dissertation, 1964.

2. Martin LB. Significance of enamel thickness in hominoid evolution. Nature 1985;314:260-3.

3. Grine FE, Martin LB. Enamel thickness and development in Australopithecus and Paranthropus. In: Grine, editor. Evolutionary history of the robust australopithecines. New York: Aldine de Gruyter; 1988. p. 3-42.

4. White TD, Suwa G, Asfaw B. Australopithecus ramidus, a new species of early hominid from Aramis, Ethiopia. Nature 1994;371:306-12.

5. Asfaw B, White T, Lovejoy O, Latimer B, Simpson S, Suwa G. Australopithecus garhi: a new species of early hominid from Ethiopia. Science 1999;284:629-35.

6. Leakey MG, Spoor F, Brown FH, Gathogo PN, Kiarie C, Leakey LN, et al. New hominin genus from eastern Africa shows diverse middle Pliocene lineages. Nature 2001;410:433-40.

7. Smith TM, Olejniczak AJ, Martin LB, Reid DJ. Variation in hominoid molar enamel thickness. J Hum Evol 2005;48: 575-92.

8. Olejniczak AJ, Smith TM, Wang W, Potts R, Ciochon R, Kullmer O, et al. Molar enamel thickness and dentine horn height in Gigantopithecus blacki. Am J Phys Anthropol 2008;135:85-91.

9. Jolly CJ. The seed eaters: a new model of hominid differentiation based on a baboon analogy. Man 1970;5: 5-26.

10. Kay RF. The nut-crackers: a new theory of the adaptations of the Ramapithecinae. Am J Phys Anthropol 1981;55: 141-51.

11. Andrews $P$, Martin L. Hominoid dietary evolution. Phil Trans Soc Lond B 1991;334:199-209.

12. Dumont ER. Correlations between enamel thickness and dietary adaptation among extant primates and chiropterans. J Mammol 1995;76:1127-36.

13. Olejniczak AJ, Smith TM, Skinner MM, Grine FE, Feeney RNM, Thackeray JF, et al. Three-dimensional molarenamel distribution and thickness in Australopithecus and Paranthropus. Biol Lett 2008;4:406-10.

14. Molnar S, Gantt DG. Functional implications of primate enamel thickness. Am J Phys Anthropol 1977;46: 447-54.

15. Macho GA, Berner ME. Enamel thickness and the helicoidal plane. Am J Phys Anthropol 1994;94:327-37.

16. Kono RT, Suwa G, Tanijiri T. A three-dimensional analysis of enamel distribution patterns in human permanent first molars. Arch Oral Biol 2002;47:867-75. 
17. Ahlgren J. Masticatory movements in man. In: Anderson DJ, Matthews BJH, editors. Mastication. Bristol: John Wright and Sons Ltd.; 1976. p. 119-30.

18. Hiiemae KH. Mammalian mastication: a review of the activity of the jaw muscles and the movements they produce in chewing. In: Butler PM, Josey KA, editors. Development, function and evolution of teeth. London, New York: Academic Press; 1978. p. 359-98.

19. Kay RF, Hiiemae K. Jaw movement and tooth use in recent and fossil primates. Am J Phys Anthropol 1974;40: 227-56.

20. Mills JR, Occlusion.Osborn J, editor. Dental anatomy and embryology, vol. 1. Blackwell Scientific Publications; 1981. p. 299-309. [book 2].

21. Molnar S, Ward SC. On the Hominid masticatory complex: biomechanical and evolutionary perspective. J Hum Evol 1977;6:551-68.

22. Grine FE. Enamel thickness of deciduous and permanent molars in modern Homo sapiens. Am J Phys Anthropol 2005;126:14-31.

23. Schwartz GT. Enamel thickness and the helicoidal wear plane in modern human mandibular molars. Arch Oral Biol 2000;45:401-9.

24. Khera SC, Carpenter CW, Staley RN. Anatomy of cusps of posterior teeth and their fracture potential. J Prosthet Dent 1990;64:139-47.

25. Shillingburg HT, Grace CS. Thickness of enamel and dentin. J South Calif Dent Assoc 1973;41:33-6.

26. Shellis RP, Beynon AD, Reid DJ, Hiiemae KM. Variations in molar enamel thickness among primates. J Hum Evol 1998;35:507-22.

27. Kono RT. Molar enamel thickness and distribution patterns in extant great apes and humans: new insights based on a 3dimensional whole crown perspective. Anthropol Sci 2004;112:121-46.

28. Smith TM, Olejniczak AJ, Reid DJ, Ferrell RJ, Hublin J-J. Modern human molar enamel thickness and enamel dentine junction shape. Arch Oral Biol 2006;51:974-95.

29. Smith TM, Olejniczak AJ, Reh S, Reid DJ, Hublin JJ. Brief communication: enamel thickness trends in the dental arcade of humans and chimpanzees. Am J Phys Anthropol 2008;136:237-41.

30. Hylander WL. The human mandible: lever or link? Am J Phys Anthropol 1975;43:227-42.

31. Mansour RM, Reynick RJ. In vivo occlusal forces and moments: I. Forces measured in terminal hinge position and associated moments. J Dent Res 1975;54:114-20.

32. Van Eijden TMJ. Three-dimensional analyses of human bite-force magnitude and moment. Arch Oral Biol 1991;36: 535-9.

33. Hattori Y, Satoh C, Kunieda T, Endoh R, Hisamatsu H, Wat M. Biteforces and their resultants during forceful intercuspal clenching in humans. J Biomech 2009;42: 1533-8.

34. Grine FE, Spencer MA, Demes B, Smith HF, Strait DS, Constant DA. Molar enamel thickness in the Chacma Baboon, Papio ursinus (Kerr 1792). Am J Phys Anthropol 2005;128:812-22.

35. Greaves WS. The jaw lever system in ungulates: a new model. J Zool (Lond) 1978;184:271-85.

36. Spencer MA. Constraints on masticatory system evolution in anthropoid primates. Am J Phys Anthropol 1999;108:483506.

37. Spencer MA. Force reduction in the primate masticatory system: electromyographic tests of biomechanical hypotheses. J Hum Evol 1998;34:25-54.

38. Pruim GJ, De Jongh HJ, Ten Bosch JJ. Forces acting on the mandible during bilateral static bite at different bite force levels. J Biomech 1980;13:673-755.
39. Kieser JA, Gebbie T, Ksiezycka K. A mathematical model for hypothetical force distribution between opposing jaws. J Dent Assoc S Afr 1996;51:701-5.

40. Kieser JA. Biomechanics of masticatory force production. J Hum Evol 1999;36:575-9.

41. Spears IR, Macho GA. The helicoidal occlusal plane-a functional and biomechanical appraisal of molars. In: Radlenski RJ, Renz H, editors. Proceedings of the 10th international symposium on dental morphology1995: 391-7.

42. Gantt DG, Harris EF, Rafter JA, Rahn JK. Distribution of enamel thickness on human deciduous molars. In: Brook A, editor. Dental morphology. Sheffield: Sheffield Academic Press; 2001. p. 167-90.

43. Aiello LC, Montgomery C, Dean C. The natural history of deciduous tooth attrition in hominoids. J Hum Evol 1991;21:397-412.

44. Mountain G, Toumba KT, Wood DJ. An investigation into bite force production in children. J Dent Res 2009;88(Special issue A):2266.

45. Mahoney P. Intraspecific variation in M1 enamel development in modern humans: implications for human evolution. J Hum Evol 2008;55:131-47.

46. Smith TM, Olejniczak AJ, Tafforeau P, Reid DJ, Grine FE, Hublin J-J. Molar crown thickness, volume, and development in South African Middle Stone Age humans. S Afr J Sci 2006;102:513-7.

47. Olejniczak AJ, Tafforeau P, Feeney RN, Martin LB. Threedimensional primate molar enamel thickness. J Hum Evol 2008;54:187-95.

48. Olejniczak AJ, Smith TM, Feeney RNM, Macchiarelli R, Mazurier A, Bondioli L, et al. Dental tissue proportions and enamel thickness in Neandertal and modern human molars. J Hum Evol 2008;55:12-23.

49. Mahoney P. Human dental microwear from Ohalo II $(22,500-$ 23,500 cal BP), Southern Levant. Am J Phys Anthropol 2007;132:489-500.

50. Mahoney P, Smith T, Schwartz G, Dean C, Kelley J. Molar crown formation in the late Miocene Asian hominoids, Sivapithecus parvada and Sivapithecus sivalensis. J Hum Evol 2007;53:61-6.

51. Suwa G, Kono RT. A micro-CT based study of linear enamel thickness in the mesial cusp section of human molars: reevaluation of methodology and assessment of within-tooth, serial, and individual variation. Anth Sci 2005;113:273-89.

52. Reid DJ, Beynon AD, Ramirez Rozzi FV. Histological reconstruction of dental development in four individuals from a Medieval site in Picardie, France. J Hum Evol 1998;35:463-77.

53. Dean MC, Schrenk F. Enamel thickness and development in a third permanent molar of Gigantopithecus blacki. J Hum Evol 2003;45:381-7.

54. Norusis MJ. SPSS for Windows professional statistics release 6.0. Chicago: SPSS, Inc.; 1993.

55. Tabachnick BG, Fidell L. Using multivariate statistics. 4th ed. Needham Heights (MA): Allyn and Bacon; 2001.

56. Kondo S, Townsend GC. Sexual dimorphism in crown units of mandibular deciduous and permanent molars in Australian Aborigines. J Com Hum Biol 2004;55:53-64.

57. Farmer V, Townsend G. Crown size variability in deciduous dentition of South African children. Am J Hum Biol 1993;5:681-90.

58. Martin LB. The relationships of the later Miocene Hominoidea. $\mathrm{Ph} . \mathrm{D}$. dissertation, University College, London, United Kingdom, 1983.

59. Dean MC, Leakey MG, Reid DJ, Schrenk F, Schwartz GT, Stringer C, et al. Growth processes in teeth distinguish modern humans from Homo erectus and earlier hominins. Nature 2001;414:628-31. 
60. Smith TM. Incremental development of primate dental enamel. PhD. Dissertation, Stony Brook University, 2004.

61. Hillson S. Dental anthropology. Cambridge: Cambridge University Press; 1996.

62. Macchiarelli R, Bondioli L, Debénath A, Mazurier A, Tournepiche JF, BirchW. et al. How Neanderthal molar teeth grew. Nature 2006;444:748-51.

63. Skinner MM, Wood BA, Boesch C, Olejniczak AJ, Rosas A, Smith TM, et al. Dental trait expression at the enamel- dentine junction of lower molars in extant and fossil hominoids. J Hum Evol 2008;54:173-86.

64. Beynon AD, Wood B. Variations in enamel thickness and structure in East African hominids. Am J Phys Anthropol 1986;70:177-93.

65. Schwartz GT. Taxonomic and functional aspects of the patterning of enamel thickness distribution in extant large-bodied hominoids. Am J Phys Anthropol 2000;111: 221-44. 